\title{
Vilen Lipatov*
}

\section{Political Support and Civil Disobedience: A Social Interaction Approach}

DOI 10.1515/bejte-2015-0082

Published online May 25, 2016

Abstract: People may express their opposition to government policies by adopting different measures of civil disobedience. Tax compliance is an example of an economic decision that may be affected by anti-government sentiment. Embedding the interdependence between social policies, political opposition and tax compliance in a dynamic social interaction process, we characterize a unique stable steady state of such a process. We find that social interaction may be a very important factor shaping government policies, at times reverting conventional relations between social spending and government support.

Keywords: government support, civil disobedience, social interaction, tax compliance

JEL Classification: H26, H50, P16

\section{Introduction}

There are different ways to express political support or lack of it. While participating in an election is the obvious mechanism for individuals to express government support or opposition, there are other civil and daily actions affected by political support. People may express their support or opposition to existing government by demonstrating or by adopting various measures of civil disobedience. ${ }^{1}$ Legal disobedience may be viewed by some people as a legitimate way of expressing their anti-government sentiment. However, legal disobedience may evoke government reaction and penalties which in turn may reinforce this sentiment. Therefore, while legal disobedience may be affected by political support, being punished for such disobedience may affect government support.

1 Clearly, in different countries there are different traditions. For example, casual observation indicates that in Italy or France there are many more demonstrations and strikes than in the US.

*Corresponding author: Vilen Lipatov, Compass Lexecon Brussels and CESifo, 23 Square de Meeûs, 1000 Brussels, Belgium, E-mail: vilenl@gmail.com 
We focus on tax compliance as the most obvious civil duty that might be affected by political support. ${ }^{2}$ The early literature on tax compliance was devoted mainly to the individuals' incentives to report their income given the government auditing probability and the penalty for tax evasion. ${ }^{3}$ But tax compliance is not just a rational decision that weights the gains from misreporting versus the expected punishment. There is intrinsic motivation to be a law obedient citizen. For many individuals, this is part of their identity and they would obey the law even without any monitoring. The intrinsic motivation to pay taxes, or tax morale, ${ }^{4}$ as intrinsic motivation for any other civil duty, may be affected by (dis)agreement with government objectives and policies. ${ }^{5}$ Individuals may be more inclined to evade taxation when they oppose the ruling regime than when they support it.

An interesting example was discussed by Besley, Preston, and Ridge (1997). While it is commonly accepted that the British public has historically been law abiding, after the Thatcher government introduced a poll tax in 1990, a widespread campaign of non-payment was initiated which together with political protest lead to the poll tax riots of 1990. Still another, perhaps the most famous example of a tax revolt that was (partly) triggered by taxation is the Tea Act that was passed by the British parliament in May 1773. This act revived the colonial issue of " taxation without representation" and the colonies demanded that the British government would remove the tax on tea. For a long list of historical examples of tax revolts, riots, rebellions, strikes and other forms od tax resistance, see Wikipedia entry "history of tax resistance". 6

The decision to support the government (and to what extent) is not only based on the analysis of government policies. ${ }^{7}$ Individuals are engaged in political debates with their friends and colleagues. People like to talk about

2 We can use our framework for analyzing other types of civil obligation. Focusing on tax compliance merely gives us the advantage of being able to discuss tax revenues as part of our analysis.

3 This approach was first introduced by Allingham and and Sandmo (1972). For surveys of this literature see Andreoni, Erard, and Feinstein (1998), Cowell (1990), Slemrod (2007) and Schneider and Enste (2000).

4 There is extensive literature in the area of tax morale, see, for example references in Alm (2010). 5 This argument is similar to the crowding out literature (Gneezy and Rustichini 2000; Frey and Jegen 2001), as opposing the government destroys part of the intrinsic motivation for tax compliance leaving only extrinsic motivation of avoiding the penalty.

6 https://en.wikipedia.org/wiki/History_of_tax_resistance, last accessed on 17 April 2016.

7 Listhang and Miller (1985), for example, reject the hypothesis that objective assessment of tax policy is important in the formation of political support. While they explain this finding by relying on the existence of ideological reasoning, we provide an alternative explanation stemming from heterogeneity of attitude and the effect of social interaction. 
politics, they like to express their political opinion, argue, demonstrate and express their political support or opposition. Political support is therefore formed by the objective assessment of government policies but also by a social interaction process in which individuals with different opinions interact with one another, express their views and try to convince each other regarding their political preference (see also Huckfeldt et al. 1995). Social interaction allows for information exchange but also facilitates a mechanism of influencing other individuals' opinions and behavior. ${ }^{8}$

Our paper is closely related to the extensive literature on tax compliance. Since the seminal paper by Allingham and Sandmo (1972), the focus of this literature is on the taxpayer as an isolated decision maker. ${ }^{9}$ This literature has been extended to include the effect of social preferences and social norms on the tax compliance decision. Erard and Feinstein (1994) discuss the role of guilt and shame of misreporting income; the empirical evidence that their model works is provided by Dulleck et al. (2016) who use psychological markers (heart rate variability) to show that psychic costs increase tax compliance. Gordon (1989) considers the psychic costs, anxiety and self-image as well as social stigma that may be associated with tax evasion; Myles and Naylor (1996) investigate the role of customs and conformity in tax compliance decision.

The role of social preferences in tax compliance decisions was experimentally examined by Fortin, Lacroix, and Villeval (2007) who extended the standard model by allowing for a social conformity and fairness effect. ${ }^{10}$ Frey and Torgler (2007) use survey data to provide evidence that pro-social behavior or conditional cooperation matters for tax morale. In particular, they find high correlation between perceived tax evasion and tax morale, as well as between institutional quality and tax morale. Cummings et al (2009) provide experimental evidence that tax compliance is shaped by the fairness of tax system, the perceived fiscal exchange and the corruption level in the political system.

We do not assume any social preferences, but we allow for a dynamic social interaction process by which individuals repeatedly interact in small groups and their political support, as well as their tax compliance decision, is affected by the type of individuals they interact with. Our focus is on the interdependence

8 See also Glaeser, Sacerdote, and Scheinkman (1996) who discuss the importance of social interaction in determining criminal behavior (and tax evasion clearly falls under the definition of criminal behavior).

9 For a recent discussion of extension to this framework see Alm and Torgler (2011).

10 Fortin, Lacroix, and Villeval (2007) used the terminology of " social interaction" to consider the case in which individuals have social preference that depend on the actions chosen by their reference group. That is, conformity and fairness are measured with respect to other individuals. In equilibrium there is therefore an additional rational expectation condition. 
between the formation of political opposition/support, tax compliance decision, government social policies and income distribution. ${ }^{11}$ We consider a model in which individuals are heterogeneous with respect to their earning and government support. There is a fixed proportion of rich individuals. Income is subject to taxation, but individuals may misreport their income. Our key assumption is that political support may affect the individuals' tax compliance decision, in line with the literature discussed in the previous paragraph. ${ }^{12}$ Thus, the individuals who politically oppose the government are more likely to consider misreporting their income.

The role of the government, in our model, is to collect and spend the taxes. The tax rate and auditing policy are exogenously given. The only government's decision is the portion of the budget to be spent on social redistributive activities, which it makes in order to maximize a weighted average of tax compliance and government support. Without social interaction, rich individuals generally prefer less social spending that imposes wealth redistribution while poor individuals prefer more of it. The government audits a fixed proportion of the income reports and punishes those individuals who engage in tax evasion.

Our assumed social interaction process implies that both social spending and auditing policies affect government support and tax compliance. Penalizing an individual for tax evasion may convince this individual to report his income correctly. At the same time, penalizing individuals increases the proportion of opposition in the population. These individuals socially interact with other individuals and may convince them to become government opposition. Having a large portion of the population who oppose the government may induce more tax evasion in future periods. ${ }^{13}$

We study how the social spending policy, the auditing probability, the proportion of rich individuals in the population and the extent of segregation affect government support, tax revenues and tax evasion. Our main result is that

11 Our approach is also related to that of statistical physics in general and multi agent-based modeling in particular (for a survey see Castellano, Fortunato, and Loreto 2009).

12 Feld and Frey (2007) show that tax morale is boosted by fair and legitimate perception of political process. Gangl, Hofmann, and Kirchler (2015) conceptualize this relation between government support (power and trust) and tax compliance in informal psychological framework. Alm and Torgler (2011) provide perhaps the most comprehensive framework for ideas, distinguishing "enforcement", "service" and "trust" paradigms in the analysis of tax compliance.

13 See Lipatov (2008) for a model of tax evasion in which there is a social interaction process by which individuals learn about the auditing policy. Alm, Jackson, and McKee (2009) used an experimental approach to study the information dissemination regarding audit frequency. This information includes also informal communication among taxpayers. 
social interaction has a very substantial impact on these effects. Indeed, sometimes allowing for social interaction reverses the sign of the relation between the variables of interest. For example, a higher level of social spending may result in more opposition even among the poor population despite the fact that poor individuals prefer higher social spending. Similarly, it is possible to increase social spending, a policy which is unpopular with rich individuals, and yet achieve lower levels of tax evasion and higher tax revenues. Finally, an increase in auditing probability may yield a large increase of opposition among the rich, which yields more tax evasion and lower tax revenues.

We further show that the effect of social spending on government support and tax collection is sensitive to the population composition (rich/poor), but not very sensitive to introducing some degree of segregation. Generally, however, segregation weakens the social interaction and, when sufficiently high, destroys the counter-intuitive effects described in the previous paragraph. This may indicate that in highly segregated societies the governments may be more justified to neglect social interaction “ distortion” of government policies. In countries where segregation does not seem to be the biggest issue, the income distribution and inequality (reduced in our model to the shares of the rich and the poor) call for attention while analysing the effects of government policies. Indeed, an interesting result of our analysis is that, in a society with a relatively similar number of poor and rich, the optimal social spending may be lower than in a society with a majority of rich individuals (which is not intuitive) or with a majority of poor individuals (which is intuitive). This is because, in unbalanced societies, social interaction amplifies the effect of changing social spending on government support, whereas in balanced societies it does not. As a result, it may be optimal to keep the social spending to minimum in the balanced case and provide more social spending when the rich are clear majority.

Our contribution to the analysis of the effect of social interaction to the dynamics of government support and civil disobedience is not limited to the qualitative results described above. By proving the existence and uniqueness of the stable steady state in our model, we bring a first brick to building analytical foundations to the large field of agent-based modelling. An agent-based model typically lacks analytical component, fully relying on numerical simulations (see Bloomquist 2006 for an example). We show, albeit in a very stylized setting, that this does not have to be the case. Our approach can in principle be applied in a richer environment (with more types of agents).

The rest of the paper is organized as follows: Section 2 provides the basic model in which we specify our assumptions regarding the social interaction among individuals and the formation of political opinion. In Section 3, we discuss the resultant population dynamics and show that under our 
assumptions there is always a unique stable steady state and that an interior stable steady state exists only for either high or low levels of social spending. In Section 4, we use a numerical analysis to analyze the effect of social spending on political support and tax compliance. Section 5 investigates the optimal government policy when the government fully internalizes the social interaction process. In Section 6, we extend our basic model to account for segregation. In conclusion, we outline further possible extensions of the model.

\section{The Model}

Consider a society of measure one, in which individuals may decide to either support or oppose the government. This decision may be affected by the policies adopted by the government as well as by social interaction. For the sake of concreteness, we assume that the only action individual have to take is to pay their taxes. Therefore, political disobedience may only take the form of tax evasion. We assume that individuals need to report their income, which is subject to taxation. The government monitors the individuals' income reports and penalizes whenever tax evasion is exposed. On the other hand, the government needs to decide on the allocation of its budget and in particular on its social spending policy. We denote this policy by $\alpha$, which is the proportion of the tax revenues that are spent on social issues. We assume that poor individuals support large social spending while rich individuals oppose it.

We further specify the types of individuals that arise in our model and their possible social interaction process.

\subsection{Individuals}

There are two types of individuals; poor individuals who earn $L$ and rich individuals who earn $H$; such that $H>L$. There is a fixed proportion, denoted by $\gamma$, of rich individuals. Individuals differ with respect to government support. We assume, for convenience, that there are only two categories; $S$ - individuals who support the government and $O$ - individuals opposing it. The shares of opposition in the rich and poor populations in period $t$ are denoted as $o_{t}^{r}$ and $o_{t}^{p}$ respectively (similarly, the share of supporters among rich and poor individuals is $s_{t}^{r}=1-o_{t}^{r}$ and $s_{t}^{p}=1-o_{t}^{p}$ respectively). The overall government support at period $t$ is given by $s_{t}=\gamma s_{t}^{r}+(1-\gamma) s_{t}^{p}$.

Each individual must report his/her income and pay the appropriate taxes. The poor truthfully report $L$ while rich individuals have a choice; they either 
report their income $H$ or they may try to lower their tax payment by misreporting their income, i. e., reporting $L$ instead of $H^{14}$

We assume that government support induces tax compliance. Moreover, for convenience we assume that government supporters always report their income correctly (clearly, this is an extreme assumption, but our results are robust to relaxing it - all that we need is that political support makes compliance more likely). Thus, only rich individuals who oppose the government consider tax evasion (or, more generally, civil disobedience) as an option.

Consequently, in the beginning of every period $t$ there are 6 different types of individuals (omitting index $t$ for convenience):

(i) $P^{O}-$ a poor individual who opposes the government,

(ii) $P^{S}$ - a poor individual who supports the government,

(iii) $R^{S}$ - a rich individual who supports the government and therefore reports his earnings accurately,

(iv) $R_{H}^{O}$ - a rich individual who opposes the government but in period $t-1$ he honestly reports his income,

(v) $\quad R_{C}^{O}$ - a rich individual who opposes the government, and in period $t-1$ he cheated on his tax report and has been caught by the government monitors,

(vi) $\quad R_{N}^{O}$ - a rich individual who opposes the government, and in period $t-1$ he cheated on his tax report but was not caught by the government.

The proportion of rich individuals who misreport their income in period $t-1$ is given by $q_{t-1}=\left(R_{C, t}^{O}+R_{N, t}^{O}\right) /\left(R_{C, t}^{O}+R_{N, t}^{O}+R_{H, t}^{O}\right)$ and it is endogenously determined.

\subsection{Social Interaction}

We consider a dynamic social interaction process by which individuals are randomly matched into pairs every period. ${ }^{15}$ The matched individuals observe each other's type and may discuss their political inclination. The outcome of

14 Thus both poor and rich individuals pay taxes. The rich individuals, however, pay higher taxes whenever they report their higher income.

15 We assume social interaction of pairs in order to simplify the population dynamics that we investigate. One can extend our model to social interaction in larger groups but this would be at a cost of considerably complicating the analysis. In Section 6, we relax the assumption of random matching and show that our results are robust to introducing modest degree of segregation. 
such an interaction is a possible transition of individuals' opinions regarding government support as well as tax compliance decisions.

We consider a two-stage social interaction process. In the first stage, political opinions are formed; in the second stage, individuals make their tax compliance decisions given their new updated opinions. We assume a Markov process in which only the current type of the matched players affects their decisions and the formation of their opinions.

\subsubsection{Opposition/Support Decision}

In the beginning of period $t$, individuals have a political opinion that was shaped in period $t-1$. As part of their social interaction, individuals discuss their political opinion, try to convince their friends and acquaintances regarding their political views but may also be convinced by others to change their views. We follow a probabilistic transition rule that is affected by government social policy, the individuals' type and the type of individuals they are matched with.

The underlying process of persuasion implies that if two individuals who have the same political opinion are matched, then they are not going to change their opinions. We also assume that individuals' income affects their government support only via the different views that rich and poor individuals have regarding social spending. In Table 1 below, we specify our assumptions regarding the transition probabilities in any matching depending on the types that are matched and the government's social policy. ${ }^{16,17}$

We assume transition probabilities with the following properties:

(i) when both individuals have the same opinion, then social interaction does not affect their opinion.

(ii) when two different types are matched, only one of them will switch his opinion. That is, we do not allow the government supporter to convince his matched partner to switch to support the government and at the same time, he himself is convinced to oppose the government.

16 There are eight possible types of mixed matches depending on the different characteristics of individuals (opposition, support), (rich, poor), (cheat, comply), (caught, not caught).

17 In the table we use for convenience the terminology $\operatorname{Pr}(S S \mid \cdot, \cdot)$ for having the two agents becoming government supporters as a result of the social interaction. Since a change of opinion happens only when individuals have a different opinion we assume for such couples that the first individual is type $O$ while the second is type $S$ and therefore we do not have a possible transition to $S O$ which implies that both individuals change their opinion. 
Table 1: The transition probabilities of government support.

\begin{tabular}{llll}
\hline Match & $\operatorname{Pr}(\boldsymbol{O O} \mid \cdot, \cdot)$ & $\operatorname{Pr}(\boldsymbol{S S} \mid \cdot, \cdot)$ & $\operatorname{Pr}(\boldsymbol{O S} \mid \cdot, \cdot)$ \\
\hline$O O$ & 1 & - & - \\
$R_{C}^{O} R^{S}$ & $\alpha \beta$ & 0 & $1-\alpha \beta$ \\
$R_{C}^{O} P^{S}$ & $(1-\alpha) \beta$ & 0 & $1-(1-\alpha) \beta$ \\
$R_{N}^{O} R^{S}, R_{H}^{O} R^{S}$ & $\alpha \beta$ & $(1-\alpha) \beta$ & $1-\beta$ \\
$R_{N}^{O} P^{S}, R_{H}^{O} P^{S}$ & $(1-\alpha) \beta$ & $(1-\alpha) \beta$ & $1-2 \beta(1-\alpha)$ \\
$P^{O} R^{S}$ & $\alpha \beta$ & $\alpha \beta$ & $1-2 \alpha \beta$ \\
$P^{O} P^{S}$ & $(1-\alpha) \beta$ & $\alpha \beta$ & $1-\beta$ \\
$S S$ & - & 1 & - \\
\hline
\end{tabular}

Note: $O O$ stands for $R^{O} R^{O}, R^{O} P^{O}, P^{O} P^{O}$ and $S S$ for $R^{S} R^{S}, R^{S} P^{S}, P^{S} P^{S}$.

(iii) individuals do not like government penalties and thus if a (rich) individual was caught for tax evasion and was punished he would not be convinced to become a government supporter.

(iv) poor individuals like redistribution, whereas rich individuals are averse to it. $^{18}$ Thus, a higher level of social spending, $\alpha$, increases the probability that a rich individual would oppose the government and increase the probability that a poor individual would support the government.

When an individual who supports the government is matched with an individual who opposes the government, the probability that the government supporter will switch to opposition is assumed to be $(1-\alpha) \beta$ if he is rich and does not like social spending and $\alpha \beta$ if he is poor and supports social spending. The parameter $\beta ; \beta<\frac{1}{2}$, is the inclination to switch. A small $\beta$ implies that it is more difficult to convince individuals to change their political opinion and there is more inertia in such opinions while a high $\beta$ implies that switching political opinion is more frequent. This parameter can also be interpreted as the strength of " memory" or past experiences.

\subsubsection{Tax Report Decision}

We assume that (i) the political opinion of a matched partner has no effect on the tax reporting decision; (ii) tax compliance decision would depend on an

18 We normalize the minimal level of social spending that the rich are willing to accept, say due to their own security concerns, to zero. A more general formulation would have $\left[\alpha_{\min }, \alpha_{\max }\right]$ instead of $[0,1]$ as the domain of social spending, but the results would not qualitatively change. 
individual's own (recent) experience and on the experience of the individuals he is matched with. Individuals who were caught for tax evasion and those who are matched with individuals who were caught and punished for tax evasion will be less likely to do so themselves.

We let $Q(x, y)$ be the probability that the type $x$ individual will misreport his income when he is matched with a type $y$ individual. Since we assume that government supporters do not consider tax evasion we get that $Q\left(R^{S}, y\right)=0$ for every possible type $y$. The three types who may consider tax evasion are the rich individuals who oppose the government, i. e., types $R_{C}^{O}, R_{H}^{O}$, and $R_{N}^{O}{ }^{19}$ We assume that type $R_{C}^{O}$, who was caught in the previous period for tax evasion, would report his income correctly independently of whom he was matched with. ${ }^{20}$ Type $R_{N}^{O}$ will continue to misreport his income unless he is matched with type $R_{C}^{O}$ who was caught and punished. Given the bad experience of his matched partner, he is going to misreport income only with probability $1-\eta$. Type $R_{H}^{O}$, who was honest in the previous period, continues to be honest if he is matched with type $R_{C}^{O}$ but otherwise there is a positive probability, $\eta$, that he would switch and try to misreport his income. Our assumptions regarding tax compliance are summarized in Table 2, which specifies the probabilities of misreporting income of each type (columns) as a function of the individual he is matched with:

Table 2: The probabilities of non-compliance.

\begin{tabular}{lrrr}
\hline & $\boldsymbol{R}_{C}^{O}$ & $\boldsymbol{R}_{N}^{O}$ & $\boldsymbol{R}_{H}^{O}$ \\
\hline$R_{C}^{O}$ & 0 & $1-\eta$ & 0 \\
$R_{N}^{O}, R_{H}^{O}, R^{S}, P$ & 0 & 1 & $\eta$ \\
\hline
\end{tabular}

The tax compliance decision in our formulation is entirely based on population dynamics and not on the expected benefit of tax evasion. We assume that the auditing probability and the government penalty are exogenously given. Note that in our setting the probability of auditing indirectly affects the tax compliance decision via the population dynamics. As $p$ goes up there are relatively more type $R_{C}^{O}$

19 We also need to specify the tax decision of a rich opposition who was a supporter in the previous period. But given that this individual (as a government supporter) reported his income correctly in the previous period, we assume that he behaves in the same manner as the honest opposition $R_{H}^{O}$.

20 This is consistent with the evidence that individual audit experience affects compliance, see e. g. Andreoni, Erard, and Feinstein (1998) and Cummings et al. (2009). 
individuals and thus the probability of type $R_{N}^{O}$ to be matched with type $R_{C}^{O}$ is higher. Such a match results in a lower probability of tax evasion. ${ }^{21}$

\subsection{Government}

In our model, the government collects taxes and determines its social policy $\alpha$ - the share of social spending out of the tax revenues. We assume that the tax policy, which includes tax rate, the probability of auditing and the penalty for tax evasion, is given exogenously. The government commits to a specific $\alpha$ at the outset of the game and it fully internalizes the social interaction process. That is, the government can calculate the steady state shares of government's supporters among the entire population, denoted as $s(\alpha)$, and the percentage of non-compliant among rich individuals, denoted as $q(\alpha)$, as functions of its social policy $\alpha$.

The government objective is to have the highest possible budget (tax revenues), but, on the other hand, it wishes to maximize the political support it gets. When all the rich people correctly report their income, tax revenues are maximized and we denote this tax potential as $T$. However, given that the proportion of rich people who misreport their income and are not caught for tax evasion is $o^{r}(\alpha) q(\alpha)(1-p)$, the government's tax revenue in steady state is given by

$$
T(\alpha)=T\left(1-o^{r}(\alpha) q(\alpha)(1-p)\right) .
$$

We let $T^{\star}(\alpha)$ be the proportion of the tax potential that the government manages to capture, i. e., $T^{\star}(\alpha)=T(\alpha) / T$. We assume that the government's objective function is additive in the two terms and is given by:

$$
G \equiv \theta T^{\star}(\alpha)+(1-\theta) s(\alpha),
$$

where $\theta$ is a parameter reflecting the relative importance of government support and tax revenues.

\section{Population Dynamics}

The transition probabilities provided by Tables 1 and 2 define a Markovian population dynamic. In each period, we have a distribution of types that socially interact and transform according to the transition matrix defined by the two tables. The state of the population is fully characterized by the triple $\left(o_{t}^{r}, o_{t}^{p}, q_{t}\right)$,

21 We may also capture such considerations by assuming that the probability of experimenting with tax evasion, $\eta(p, D)$, is a decreasing function of the probability of auditing and the penalty of misreporting. 
which defines (i) the percentage of government opposition among the rich in period $t$; (ii) the percentage of government opposition among the poor in period $t$; and (iii) the probability that at period $t$ a rich individual who opposes the government will be engaged in tax evasion. That is, $\left(o_{t}^{r}, o_{t}^{p}, q_{t}\right)$ uniquely defines the distribution of all the types of individuals.

\subsection{The Dynamics of Government Support}

We first construct the transition probabilities of government opposition, $o_{t+1}^{r}\left(o_{t}^{r}, o_{t}^{p}, q_{t}\right)$, and $o_{t+1}^{p}\left(o_{t}^{r}, o_{t}^{p}, q_{t}\right)$, i. e., the percentage of government opposition among rich individuals in period $t+1$ as a function of the distribution of types at period $t$. Collecting the terms summarized in Tables 1 and A1, we obtain the following expressions for the transition probabilities: ${ }^{22}$

$$
\begin{aligned}
o_{t+1}^{r}= & \gamma\left(o_{t}^{r}\right)^{2}+(1-\gamma) o_{t}^{r} o_{t}^{p} \\
& +\gamma o_{t}^{r}\left(1-o_{t}^{r}\right)\left(p q_{t}(1+\alpha \beta)+\left(1-p q_{t}\right)(2 \alpha \beta-\beta+1)\right) \\
& +(1-\gamma) o_{t}^{r}\left(1-o_{t}^{p}\right)\left(1-\left(1-p q_{t}\right)(1-\alpha) \beta\right)+(1-\gamma) o_{t}^{p}\left(1-o_{t}^{r}\right) \alpha \beta, \\
o_{t+1}^{p}= & (1-\gamma)\left(o_{t}^{p}\right)^{2}+\gamma o_{t}^{r} o_{t}^{p}+\gamma o_{t}^{r}\left(1-o_{t}^{p}\right)(1-\alpha) \beta \\
& +\gamma o_{t}^{p}\left(1-o_{t}^{r}\right)(1-\alpha \beta)+(1-\gamma) o_{t}^{p}\left(1-o_{t}^{p}\right)(1-2 \alpha \beta+\beta) .
\end{aligned}
$$

\subsection{The Dynamics of Tax Compliance}

In every period $t, q_{t}$ describes the probability that a rich individual who opposes the government would misreport his/her income. This probability is an outcome of the social interaction process. We can use Tables 1 and 2 to define the transition probability $q_{t+1}\left(o_{t}^{r}, o_{t}^{p}, q_{t}\right)$ (see Appendix A3 for details):

$$
\begin{aligned}
q_{t+1}\left(o_{t+1}^{r}, o_{t+1}^{p}, q_{t}\right)= & \gamma o_{t+1}^{r}\left(q_{t}+\eta-q_{t} \eta-p q_{t}+p^{2} q_{t}^{2} \eta-p q_{t} \eta\right) \\
& +(1-\gamma) o_{t+1}^{p}\left(\left(1-q_{t}\right) \eta+(1-p) q_{t}\right) \\
& +(1-p) q_{t} \gamma\left(1-o_{t}^{r}\right)(1-\beta(1-(1+\eta) \alpha)) \\
& +\gamma\left(1-q_{t}\right)\left(1-o_{t}^{r}\right)(2 \alpha \beta+1-\beta) \eta+(1-\gamma) \frac{o_{t+1}^{p}}{o_{t+1}^{r}}\left(1-o_{t}^{r}\right) \alpha \beta \eta \\
& +\left(\left(1-q_{t}\right) \eta+(1-p) q_{t}\right)(1-\beta+\alpha \beta)\left(1-o_{t+1}^{p}\right)(1-\gamma),
\end{aligned}
$$

which can be rewritten as a function of $o_{t}^{r}, o_{t}^{p}, q_{t}$ only using eqs [3] and [4]. ${ }^{23}$

22 See Appendix A2 for details.

23 We do not write it explicitly to save space. 


\subsection{Steady State}

Definition 1: A steady state is a triple $\left(o^{r}, o^{p}, q\right)$ that remains unchanged under our Markovian transition probabilities defined by eqs [3]-[5].

Definition 2: A stable steady state is $\left(o_{t}^{r}, o_{t}^{p}, q_{t}\right)$ which is a steady state and satisfies the following stability condition: if there is a population of types which is in a $\varepsilon$ neighborhood of the steady state, then the population dynamics given by eqs [3], [4] and [5] will converge back to $\left(o_{t}^{r}, o_{t}^{p}, q_{t}\right)$.

The steady state conditions imply that full support and full opposition (with corresponding compliance levels) are always a steady state - but not necessarily a stable one. We refer to such steady states as corner solutions and steady states for which $o^{r} \in(0,1), o^{p} \in(0,1)$ will be referred to as interior steady states. An interior stable steady state implies that there is a mixed population; some are government supporters while others are government opposition.

Proposition 1: (i) There always exists a unique stable steady state $\left(o^{r}, o^{p}, q\right)$, which is the solution to the system of eqs [3]-[5]. (ii) There are $\alpha_{1}$ and $\alpha_{2} ; \alpha_{2} \geq \alpha_{1}$, such that a (unique) interior stable steady state exists only when either $\alpha<\alpha_{1}$ or when $\alpha>\alpha_{2}$.

Proof: See Appendix A4.

An interior steady state exists for either small or high levels of social spending. At such levels, the government policy plays an important role in the formation of political opinion. Rich individuals resent high levels of $\alpha$ while poor individuals resent low levels of $\alpha$. In the middle range, the resentment of both groups with respect to the government social policy is weaker which gives room for a more important role of the dynamic persuasion process implied by our population dynamics. In these cases, the social interaction process converges to a boundary steady state in which all individuals have the same political opinion.

\section{Results}

Our analysis focuses on the effect of the social spending policy, $\alpha$, and the proportion of rich individuals in the population, $\gamma$, on government support and 
tax evasion. We conduct a numerical analysis in which we find the stable steady state (existence and uniqueness of which is guaranteed by Proposition 1) for different sets of parameters and investigate the effects of different policies and parameters on the steady state that we get.

We determine the following parameter values for our numerical analysis:

- $\quad p$ - We vary auditing probability over its whole domain. The benchmark value is set to $0.2 .^{24}$

- $\quad \gamma$ - The percentage of rich individuals in the society will be between $40 \%$ and $60 \%$. Our " rich" include middle class, so we think of countries with compressed income distribution (Northern Europe, Germany) as those that have a higher share of the rich, and of countries with higher income inequality (USA, developing countries) as those that have a lower share of the rich.

- $\quad \beta-0.2-0.4$. Given that $\beta \in\left(0, \frac{1}{2}\right)$ by construction, we thus cover a wide and seemingly reasonable range of values for the switching parameter.

- $\quad \eta-0-0.25$; as experimentation probability ought to be relatively small.

Our benchmark case is with the parameter values $\{p=0.2, \gamma=0.4, \beta=0.3, \eta=0.1\}$.

\subsection{Social Spending $\alpha$}

In an environment without social interaction, the effect of social spending $\alpha$ on government support is relatively simple; poor individuals support a higher $\alpha$ while rich individuals oppose it. Consequently, any increase of $\alpha$ induces higher government support among the poor and lower support among the rich.

In our model, however, there are two additional effects. First, there is a population dynamics whereby people may convince each other regarding their political opinion. The second effect is through the interdependence between political opinion and tax compliance. A higher $\alpha$ implies that there are more rich individuals who oppose the government and therefore it would imply a larger pool of rich individuals who may choose to misreport their income. When there are more $R_{C}^{O}$ type individuals, individuals who have been caught and punished by the government for tax evasion, then the opposition decision

24 The auditing policy varies among countries. Moreover, we should not look at the average auditing policy, but, given our model, we should look at the auditing probability of rich individuals that is higher in many countries than the average auditing probability. 
(a). Poor opposition

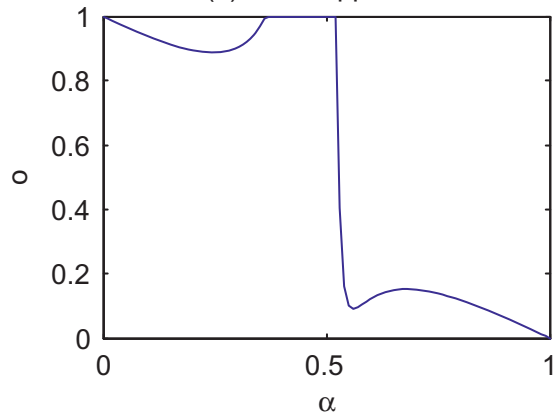

(c). Total opposition and tax collection

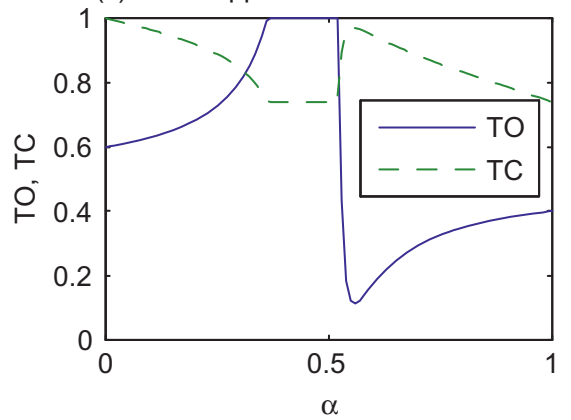

(b). Rich opposition

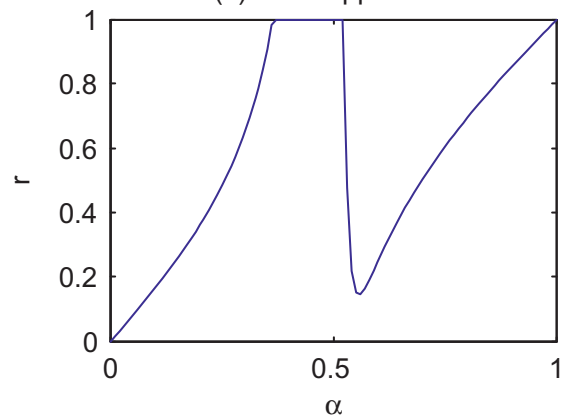

(d). Non-compliance $q$

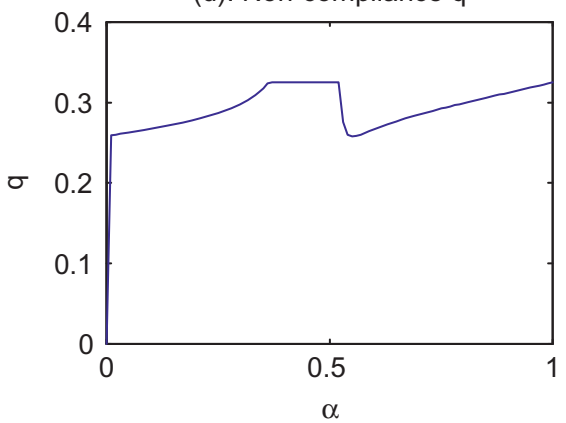

Figure 1: $\gamma=0.4$.

becomes reinforced as this type of individual remains in opposition regardless of whom he/she is matched with. ${ }^{25}$

In Figure 1 we present our baseline case. We vary the social spending $\alpha$ between 0 and 1 and calculate the stable steady state for each level of $\alpha$. Figure 1 (a) depicts the level of opposition from the poor population as a function of $\alpha$. Figure 1(b) depicts the opposition level of rich individuals. Figure 1(c) depicts the total level of government opposition (which is the weighted sum of the two types of individuals) and the total amount of tax revenues collected by the government given by $T C=(1-q+p q) o^{r}+1-o^{r}=1-q(1-p) o^{r}$. Figure 1 (d) provides

25 The assumption that a punished individual never chooses to support the government in the next period may seem unreasonable, because the attitude towards the tax authority is distinct from the attitude towards the government. However, this is consistent with our assumption that government supporters are always compliant. Moreover, assuming that a (substantial) share of punished individuals (rather than all of them) have to stay in opposition does not change our results qualitatively. 
information on the level of tax evasion and depicts the percentage of actual cheaters, $q$, among the rich-opposition population.

Note that when $\alpha=0$, the unique stable steady state is a complete division of government support: poor individuals oppose the government while all the rich individuals support it. In this case, the opinion of each individual is so strong that there is no scope for persuasion. Consequently, social interaction does not matter. Government maximizes its tax revenues since all the rich people support the government and are not engaged in tax evasion. When $\alpha=1$ (the government uses all its tax revenues on social spending), the only stable steady state is such that all the rich individuals oppose the government while the poor individuals support it. Again, social interaction is immaterial; tax revenues are minimized.

The effect of $\alpha$ on government support is not monotonic. Raising $\alpha$ from zero yields at the beginning the intuitive effect - poor individuals increase their support while rich individuals reduce their support. But government support among the poor is not monotonically increasing in $\alpha$. At this benchmark case $60 \%$ of the individuals are poor and prefer a higher $\alpha$, yet a further increase of $\alpha$ does not always imply a higher government support among the poor (see Figure 1(a)). More generally, Figure 1 allows us to formulate the following observation.

Observation 1 In our benchmark setting, (i) Social spending affects government's popularity in a non-monotonic way. This property holds for both the poor and the rich populations. (ii) Overall government support is maximized when social spending is in the middle range, i. e., at $\alpha \approx 0.57$ - but a small decrease of social spending implies a large reduction of the government's popularity. (iii) Tax collection is affected by the level of social spending; it is maximized at $\alpha=0$ but an increase of social spending does not always reduce tax collection. Tax revenues reach almost the same maximum level also at $\alpha \approx 0.57$, but increasing social spending beyond that level implies a decrease in overall popularity, lower tax revenues and more tax evasion.

The main conclusion from the above observation is that increasing social spending does not necessarily imply a greater government support by poor individuals even though they favor such spending. It is the indirect effect of social interaction that may generate public opinion changes not in accordance with the direct political views.

Our assumptions regarding the population dynamic process play an important role in deriving the above results. An increase of $\alpha$ increases government support among the poor who convince some of the rich individuals to support the government despite the fact that rich people object to high $\alpha$. This support also affects tax revenues as individuals who support the government do not engage in tax evasion. We thus have two effects of increasing social spending on government opposition: the direct effect, which is positive for the rich and 
negative for the poor, and indirect effect, which is determined by the social interaction process. The overall relationship between government social policy and government support (as well as tax returns) depends on the balance between the direct and indirect effects.

Formally, consider the effects that determine government support among the poor. From eq. [4], we can see that the direct effect of a marginal increase in social spending $\alpha$ is negative which indicates that the poor opposition is decreasing:

$$
\frac{\partial o_{t+1}^{p}}{\partial \alpha}=-\beta\left[\gamma o_{t}^{r}\left(1-o_{t}^{p}\right)-\gamma o_{t}^{p}\left(1-o_{t}^{r}\right)-2(1-\gamma) o_{t}^{p}\left(1-o_{t}^{p}\right)\right]<0 .
$$

Similarly, from eq. [3], we can see that the direct effect of a marginal increase in social spending $\alpha$ on government support among the rich is negative and the rich opposition is increasing:

$$
\frac{\partial o_{t+1}^{r}}{\partial \alpha}=\beta \gamma o_{t}^{r}\left(1-o_{t}^{r}\right)\left(2-p q_{t}\right)+\beta(1-\gamma)\left[o_{t}^{r}\left(1-o_{t}^{p}\right)\left(1-p q_{t}\right)+o_{t}^{p}\left(1-o_{t}^{r}\right)\right]>0 .
$$

From the discussion above, we see that the direction of the total effect does not coincide with the direction of the direct effect when $\alpha$ is close to 0.5. The reversion must come from the social interaction effect, i. e. the effect of $o_{t}^{r}$, $o_{t}^{p}$ on their future values. This "own” effect for the poor is

$$
\frac{\partial o_{t+1}^{p}}{\partial o_{t}^{p}}=\gamma\left[\beta o_{t}^{r}(2 \alpha-1)+(1-\alpha \beta)\right]+(1-\gamma)\left[1+\beta\left(2 o_{t}^{p}-1\right)(2 \alpha-1)\right],
$$

which is positive. Similarly, the own effect for the rich is

$$
\begin{aligned}
\frac{\partial o_{t+1}^{r}}{\partial o_{t}^{r}}= & 2 \gamma o_{t}^{r}+(1-\gamma) o_{t}^{p}(1-\alpha \beta) \\
& +\gamma\left(1-2 o_{t}^{r}\right)\left(1-\beta+2 \alpha \beta+(1-\alpha) \beta p q_{t}\right) \\
& +(1-\gamma)\left(1-o_{t}^{p}\right)\left(1-\beta+\alpha \beta+(1-\alpha) \beta p q_{t}\right),
\end{aligned}
$$

which is positive as well. Thus, the own effect can only reinforce the direct effect of $\alpha$.

The cross-effect on the poor is

$$
\frac{\partial o_{t+1}^{p}}{\partial o_{t}^{r}}=\beta \gamma\left(1-\alpha-o_{t}^{p}+2 \alpha o_{t}^{p}\right) .
$$

This is positive and reinforced by the higher share of the rich $\gamma$. The cross-effect on the rich is

$$
\frac{\partial o_{t+1}^{r}}{\partial o_{t}^{p}}=\beta(1-\gamma)\left(\alpha\left(1-o_{t}^{r}\right)+(1-\alpha)\left(1-p q_{t}\right) o_{t}^{r}\right),
$$

which is positive and decreasing in $\gamma$. 
Since the direct effect of on $\alpha$ and $o_{t}^{r}$ is positive and on $o_{t}^{p}$ is negative, the cross-effects transmit into the countervailing effects of social spending. This "counter-intuitive" social-interaction-effect is increasing in $\gamma$ for the poor, therefore we see larger "anomalies" (bigger amplitude of changes) on the pictures illustrating the poor opposition with higher $\gamma$, Figures 1(a), 2(a), A1a. Symmetrically, the counter-intuitive effect for the rich is decreasing in $\gamma$, so we see larger changes with lower $\gamma$ on the pictures illustrating the rich opposition, Figures 1(b), 2(b), A1b.

(a). Poor opposition

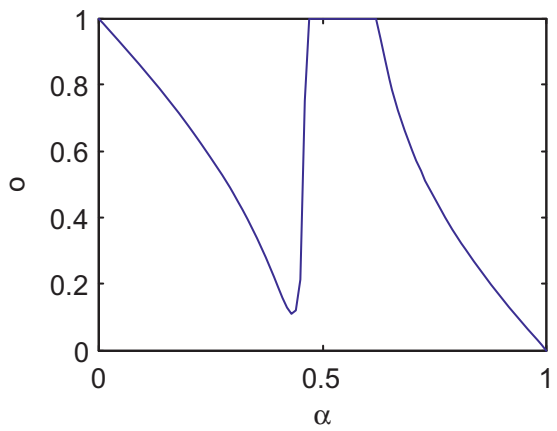

(c). Total opposition and tax collection

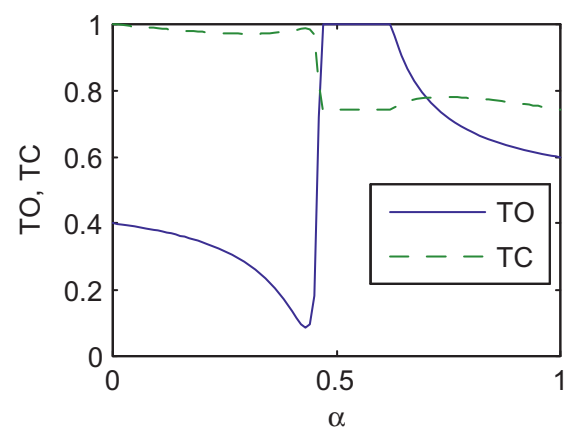

(b). Rich opposition

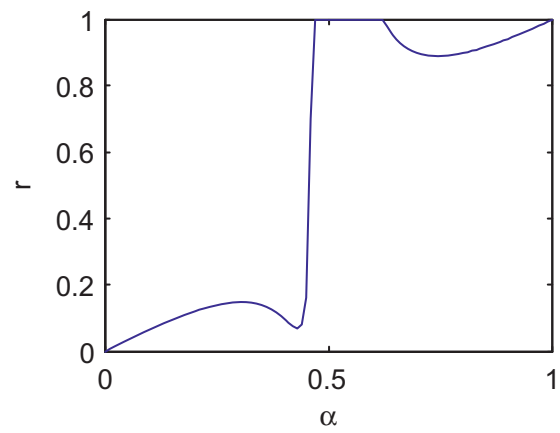

(d). Non-compliance q

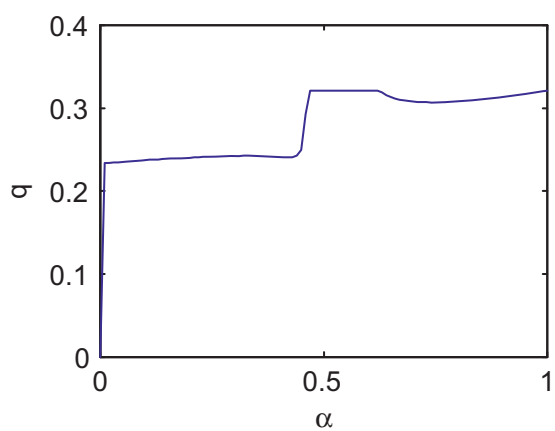

Figure 2: $\gamma=0.6$.

Finally, for the rich, there is an additional effect through a change in compliance:

$$
\frac{\partial o_{t+1}^{r}}{\partial q_{t}}=(1-\alpha) \beta p o_{t}^{r}\left(\gamma\left(1-o_{t}^{r}\right)+(1-\gamma)\left(1-o_{t}^{p}\right)\right),
$$


which is positive, increasing in $p$ and decreasing in $\alpha$. Since $\alpha$ directly increases non-compliance, as can be seen from eq. [5], this transfers into a positive effect.

To sum up, increasing $\alpha$ has three effects on the next period share of the opposition among the poor: (i) the direct negative effect; (ii) the negative effect through decreased $o_{t}^{p}$; (iii) the positive effect through increased $o_{t}^{r}$. Increasing $\alpha$ has four effects on the next period share of the opposition among the rich: (i) the direct positive effect; (ii) the positive effect through increased $o_{t}^{r}$; (iii) the negative effect through increased $o_{t}^{p}$; (iv) the positive effect through increased $q_{t}$.

Clearly, the " unintuitive" parts of our graphs (poor opposition increasing and rich opposition decreasing in response to an increase of social spending) should be attributed to (iii), which is completely due to the interaction between the rich and the poor.

We now turn to consider the case in which the majority of the population $(60 \%)$ is rich i. e., $\gamma=0.6$. The effect of changing the population composition is beyond the direct effect on each group separately as having groups of different sizes affects the underlying social interaction process. In Figure 2 below, we present the steady state government's popularity, tax revenues and tax evasion as a function of $\alpha$ when $\gamma=0.6$.

Inspecting Figure 2 allows us to formulate the following observation.

Observation 2 With $\gamma=0.6$, (i) For $\alpha=0$ all the poor individuals oppose the government. Increasing $\alpha$ in the range of $\alpha<0.4$ dramatically increases government support among the poor. When $\alpha=0.4$ more than $80 \%$ of the poor are government supporters. (ii) A further increase of $\alpha$ from $\alpha=0.4$ to $\alpha=0.6$ induces a dramatic reduction in government support among the poor (from $80 \%$ to $0 \%$ ) even though the poor support larger social spending. (iii) For low levels of $\alpha$, tax collection is not affected much by $\alpha$, but increasing $\alpha$ beyond 0.4 implies a $20 \%$ drop of tax collection.

Observation 3 Comparing Figures 1 and 2 tells an interesting story about the role of social interaction. For example, the support of the rich individuals when $\gamma=0.6$ is a mirror picture of the support of poor individuals when $\gamma=0.4$. When the poor are majority (Figure 1) and the government policy is $\alpha=0.4$, all of the poor oppose the government. In contrast, when the poor are minority (Figure 2), most of the poor population supports the government at the same level of government spending $\alpha=0.4$. Therefore, the following observation.

Whenever political opinion is determined by a social interaction process government support of each segment of the society crucially depends on the ratio of rich and poor in the population and not just on the policies implemented by the government.

As Figures 1 and 2 indicate, the population dynamic process gives rise to a “tipping point” behavior, i. e. a large change in steady state values of opposition 
as a response to a small change of the social policy. In Figure 1, for example, the large dip in both poor and large opposition is due to the large cross-effect on the support among the poor and modest cross-effect on the support among the rich (both due to the fact that $\gamma$ is sufficiently large). Thus, the rich are massively convinced by the poor to switch to support the government, but not vice versa. Figure 2 illustrates this effect further: since $\gamma$ is sufficiently large, a large spike happens when the poor are massively convinced by the rich to switch to opposition, but not vice versa.

Further, Figure A1 illustrates that “ tipping point” behavior is less pronounced, but is not eliminated completely in populations with no clear majority. Indeed, there is no drastic dip or spike in this case, as the maximum of the two corresponding cross-effects reaches its minimum at $\gamma=0.5$. However, there always exists a value $\check{\alpha}, 0<\check{\alpha}<\alpha_{1}$ such that for $\alpha \in\left(\check{\alpha}, \alpha_{1}\right)$, increasing social spending increases opposition among the poor. Similarly, there exist $\hat{\alpha}, \alpha_{2}<\hat{\alpha}<1$ such that for $\alpha \in\left(\alpha_{2}, \hat{\alpha}\right)$, increasing social spending decreases opposition among the rich.

Intuitively, this result is an extension of our initial finding that in the middle range we always obtain convergence to the complete opposition. It turns out that around this middle range of $\alpha$ the role played by social interaction is the largest: it overturns the direct effect of social spending. In particular, around the complete opposition, interaction forces work in the direction of more opposition, again because the opinions are not strong enough to promote government support.

Although our model is very stylized and its predictions should not be used in the real world policy debates, our findings suggest that the governments facing more wealth inequality (USA and developing countries) would maximize the total support at higher levels of social spending than the governments facing compressed wealth distribution (Northern Europe).

\subsection{The Tendency to Misreport Income $\eta$}

The parameter $\eta$ captures the tendency of rich individuals to misreport their income. According to Table 2, a $R_{H}^{O}$ type (a rich individual who opposes the government and did report his income correctly at period $t-1$ ) is going to "experiment" with cheating with probability $\eta$ unless he is matched with an individual who was caught and penalized for cheating (an $R_{C}^{O}$ type). ${ }^{26}$

26 On the other hand, whenever an individual who cheated without being caught is matched with an individual who was caught for cheating in period $t-1$, he becomes more careful and cheats in the next period with probability $1-\eta$. 
Having $\eta=0$ implies that an individual who did not cheat is not going to change his behavior regardless of whom he is matched with. At the same time, an individual who cheated without being caught will continue to cheat as long as he remains in opposition. However, this individual will eventually meet government supporters and there is always a positive probability that he will be convinced to become a government supporter (see Table 1). Being a government supporter implies an honest income report. Consequently, whenever $\eta=0$ the only steady state would be when all the rich individuals report their income correctly. The following observation is in order.

Observation 4 An increase of $\eta$ (experimentation with tax evasion) implies a higher opposition level for both rich and poor individuals despite the fact that $\eta$ affects only tax compliance among the rich and has no direct effect on political opinion.

Observation 4 illustrates the interdependence between tax evasion and government support, which is the focus of our model. The parameter $\eta$ relates only to the tax report decision. In particular, it does not affect the poor individuals directly, since they, by the assumptions of our model, must report their income correctly. Observation 4 shows how experimentation in tax evasion by rich individuals affects government support of the rich as well as the poor individuals. It is the social interaction that introduces the link between the political opinion of the poor and the rate of tax evasion among the rich.

\subsection{The Auditing Probability}

The direct effect of auditing is clear - a higher auditing probability reduces the incentives for tax evasion, as there is a higher probability of being caught and punished. Our focus in this section is on the indirect effect of the auditing probability. For this purpose, we ignore the direct effect even though we can incorporate it into our framework. ${ }^{27}$ A higher auditing probability implies that a higher percentage of individuals who misreport their income are being caught which implies the following two effects. The first effect is that individuals who have been caught will not cheat on their taxes in the coming period. Moreover, these individuals socially interact with other individuals and reduce the probability that those individuals will tax evade in the coming period. The second effect is on political opinion; people who were caught for tax evasion remain government opposition in the next period without even considering supporting the government.

27 As was previously discussed, we can incorporate the direct effect of $p$ by assuming that the tendency to misreport income, denoted by $\eta$, is a function of the probability of monitoring $p$. 
In Appendix A5 (Figure A2), we present the effect of government auditing on government support, tax collection and tax evasion. We assume for this calculation the benchmark parameters for which $\gamma=0.4$ and $\alpha=0.6$. The following observation is in order.

Observation $5(i)$ The levels of opposition among the poor and among the rich are both increasing with the probability of auditing $p$. (ii) The effect of the auditing probability $p$ on total tax collection is not monotonic. At low levels of $p$ total tax revenues go down with $p$. At higher levels, as expected, tax revenues go up with $p$. (iii) Tax evasion goes down with $p$.

Observation 5(iii) indicates that tax evasion goes down with the auditing probability. We get this effect without assuming any direct effect of auditing on the individuals' decision to misreport income. The negative effect of auditing is due to the social interaction process. Observation 5(i) claims that the level of opposition for both rich and poor individuals increases with the auditing probability. While the effect among the rich is clear, as we assumed that individuals who were penalized for tax evasion will tend to be government opposition, poor individuals are not affected directly by the auditing probability. Yet our analysis indicates that a higher $p$ implies that more of them become government opposition. The reason for this effect is the assumed characteristic of the social interaction process. Poor individuals' political support is affected by rich individuals who they are matched with. Since the high $p$ implies that more rich individuals become government opposition, the social dynamics implies that such views would be more common also among poor individuals.

Observation 5(ii) indicates that there is an interesting non-monotonicity of total tax revenues with respect to the auditing probability. The direct effect is that given everything else equal, a higher percentage of the rich individuals who misreport their income are forced to pay the full tax payment. Additionally, there is an indirect effect. At lower levels of $p$ an increase of $p$ triggers a large increase of opposition level among the rich (see Figure A2b). More opposition among the rich implies a larger number of rich individuals who consider the option of tax evasion, which results in lower tax collection. At lower levels of $p$ it is this indirect effect that dominates and a higher $p$ implies lower tax revenues.

\section{Optimal Social Spending Policy}

Consider now the government's optimal social spending policy. We assume that the government fully internalizes the social interaction process and can predict the properties of its steady state; $T^{\star}(\alpha)$ and $s(\alpha)$, where $T^{\star}(\alpha)$ is the percentage of tax 
potential that is collected as a function of $\alpha$ and $s(\alpha)$ is the level of government support at the steady state as a function of $\alpha$. Assume that the government does not have an explicit political agenda and that its objective function is given by eq. [2].

We numerically solve for the optimal $\alpha$ as a function of $\gamma$ and $\theta$. Given the parameter $\gamma$ (the percentage of rich individuals in the population), we calculate the steady state associated with each possible value of $\alpha$. We then find the $\alpha$ that gives the highest possible value to the government's objective function with the appropriate $\theta$.

Our results indicate that for low levels of $\gamma$ (when the majority of the population is poor) the optimal $\alpha$ does not vary much with $\theta$ (illustrated by Figure A4 in Appendix A5). However, when the population is (almost) equally divided between rich and poor the optimal $\alpha$ is highly sensitive to changes of $\gamma$ and $\theta$. In order to have a better understanding of these effects, let us look at the optimal $\alpha$ as a function of the composition of the population $\gamma$ keeping $\theta$ constant at $\theta=0.5$.

As Figure 3 indicates, the optimal $\alpha$ does not change much with $\gamma$ whenever $\gamma<0.42$. At the same time, when the population mix of rich and poor individuals becomes relatively balanced the optimal $\alpha$ becomes 0 . When $\gamma$ goes up to 0.6 the optimal $\alpha$ goes up again. Thus, Figure 5b describes a very special pattern of the optimal social spending level which is highly sensitive to the composition of rich and poor in the society. When $40 \%$ of the population is rich, the optimal share of social spending is around $60 \%$; when the population is equally divided

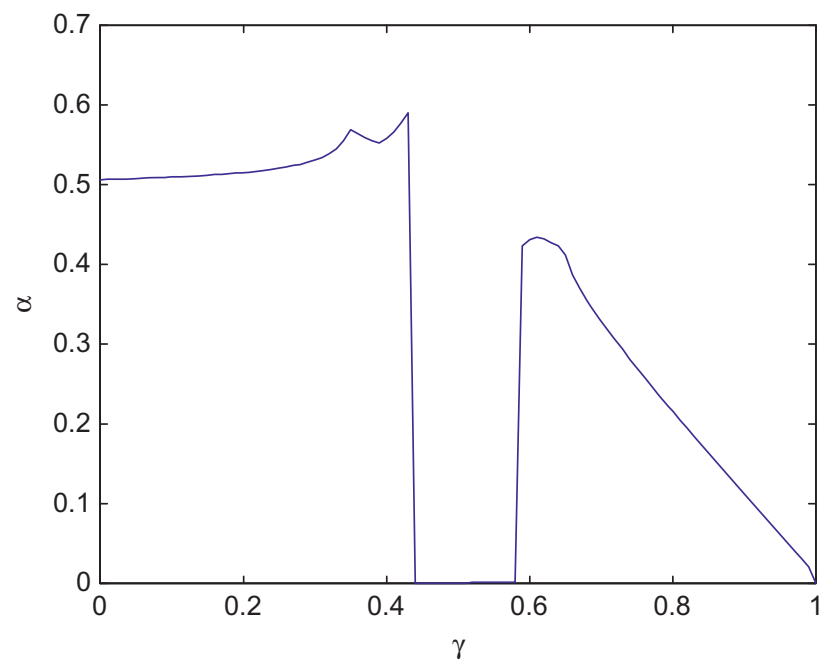

Figure 3: Optimal $\alpha$ as a function of $\gamma$ (with $\theta=0.5$ ). 
between rich and poor, the optimal social spending becomes zero; and when the percentage of rich individuals increases to $60 \%$, the optimal social spending goes up to $40 \%$. In order to understand this result let us examine Figure A1 in Appendix 5 which describes the case of $\gamma=0.5$.

From Figure A1c we can see that the overall government support is maximized at $\alpha=0$ or $\alpha=1$ while tax revenues are maximized at $\alpha=0$. Thus regardless of the weights the government will put on its two objectives, $T^{\star}(\alpha)$ and $s(\alpha)$, the optimal policy would be $\alpha=0$. We can compare Figure $1(\gamma=0.4)$ and Figure A1 $(\gamma=0.5)$ and see that in Figure 1 the government support is maximized at $\alpha=0.55$ and thus for this case we would have an interior solution where the government needs to balance its two objectives. This brings us to the following proposition

Proposition 2: The optimal social spending is not an increasing function of the proportion of poor individuals. In particular, in a society with a relatively similar number of poor and rich the optimal social spending may be lower than in a society with a majority of rich individuals or with a majority of poor individuals.

Proof: By construction as shown by Figure 3.

Again, with all reservations stemming from the cursory nature of the model, the results might indicate that if the governments were maximizing a combination of population support and tax revenues, the countries characterized by substantial (USA) but not extreme (some developing countries) wealth distribution would find it optimal to put social spending to minimum.

\section{Extension: Non-random Matching}

The social interaction process assumed in this paper so far is characterized by "no segregation". Poor individuals interact with rich individuals and the probability of matching between them depends solely on the relative size of the two groups. In this section, we introduce a segregation parameter that governs the social interaction process. The idea of segregation is embodied in parameter $\varepsilon>0$ : its higher value corresponds to more isolated groups of the rich and the poor; the lower means that each type of individuals is more open to interacting with another type. At one extreme $\left(\varepsilon=\frac{1}{\gamma}\right)$, we have complete segregation: a rich never discusses her political support decision with a poor and vice versa. At the other extreme $(\varepsilon=1)$, the interaction groups are formed by random matching, so 
the own type does not affect the distribution of types that the expected partner is characterized by. Technically, we could also have $\varepsilon<1$, which would characterize " reverse segregation" : a situation in which one prefers to interact with another type rather than with her own type.

Formally, we introduce a couple of parameters $\varepsilon_{i}$ that characterize inclination of individuals of type $i \in\{H, L\}$ to mingle with their own type. Namely, a rich person meets another rich person with probability $\gamma \varepsilon_{H}$; she meets a poor person with complementary probability $1-\gamma \varepsilon_{H}$. A poor person meets another poor person with probability $(1-\gamma) \varepsilon_{L}$; she meets a rich person with complementary probability $1-(1-\gamma) \varepsilon_{L}$. In the population, there will be $\gamma^{2} \varepsilon_{H}$ “ only rich" pairs, $(1-\gamma)^{2} \varepsilon_{L}$ “ only poor" pairs, and $1-\gamma^{2} \varepsilon_{H}-(1-\gamma)^{2} \varepsilon_{L}$ of mixed pairs.

We derive the population dynamics in this formulation and then apply a consistency condition $\varepsilon_{L}=\frac{1-2 \gamma+\gamma^{2} \varepsilon_{H}}{1-2 \gamma+\gamma^{2}}$, stemming from the fact that the share of the mixed matches in the population is the same whether calculated by multiplying the share of the rich by the probability for a rich individual to meet a poor individual or by multiplying the share of the poor by the probability for a poor individual to meet a rich individual,

$$
\gamma\left(1-\gamma \varepsilon_{H}\right)=(1-\gamma)\left(1-(1-\gamma) \varepsilon_{L}\right) .
$$

We then define segregation parameter ${ }^{28} \varepsilon:=\varepsilon_{H} \in\left[1, \frac{1}{\gamma}\right]$ : Since we are not interested in reverse segregation, the lower bound is unity; the upper bound is determined by nonnegativity of probability space.

The effect of segregation in our model is quite intuitive: it levels down the social interaction effects that drive " perverse" responses of government support to the changes in social spending. In Figure A5 in Appendix A5, the relation between model variables and social spending is depicted for $\varepsilon=2$. Compared to random matching, the social interaction "distortion" to the monotonic relation of $\alpha$ and either type of $o$ in the middle range of $\alpha$ is much less pronounced. Consequently, the social interaction effect on tax collection and tax compliance also becomes less pronounced with an increase in segregation.

Interestingly, at benchmark parameter values and middle range of social spending, the relation between segregation and the poor opposition is not monotonic. For example, for $\alpha=0.6$ the poor opposition first increases and then decreases as segregation becomes stronger, as illustrated on Figure 4. This is because despite segregation weakens interaction between the rich and

28 We could equivalently define the segregation parameter as $\varepsilon_{L}$ and express everything in terms of inclination of the poor to match with their own type. 
(a). Poor opposition

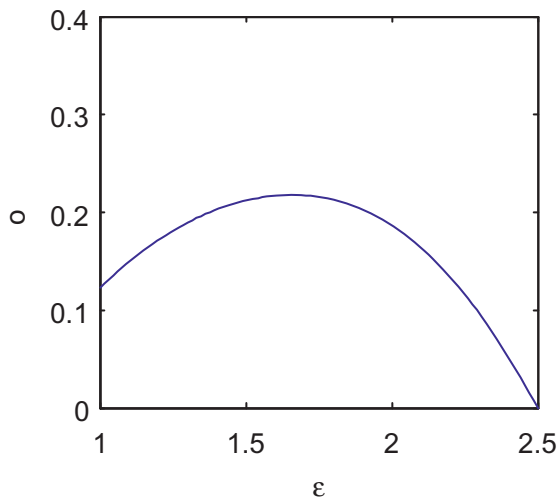

(c). Total opposition and tax collection

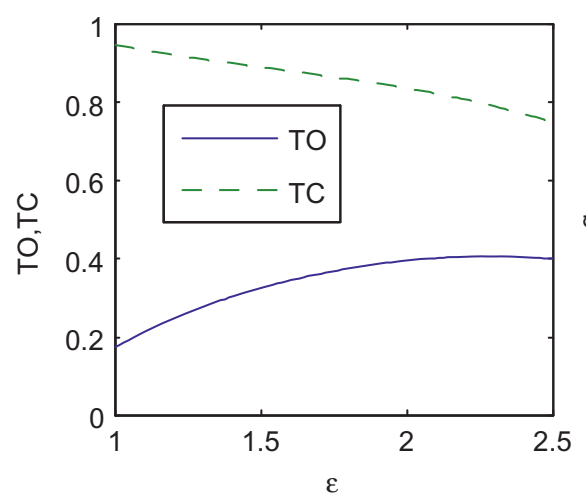

(b). Rich opposition

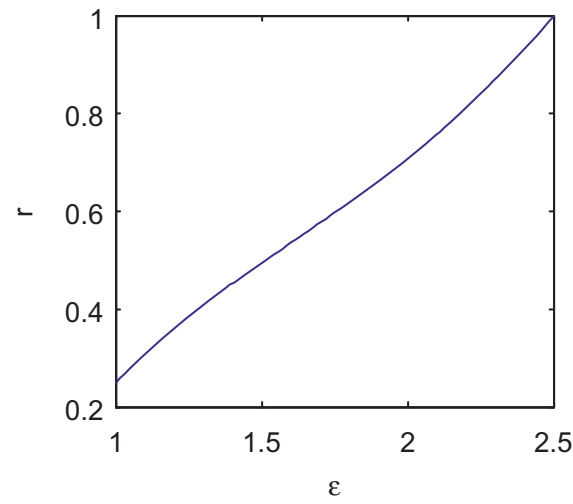

(d). Non-compliance q

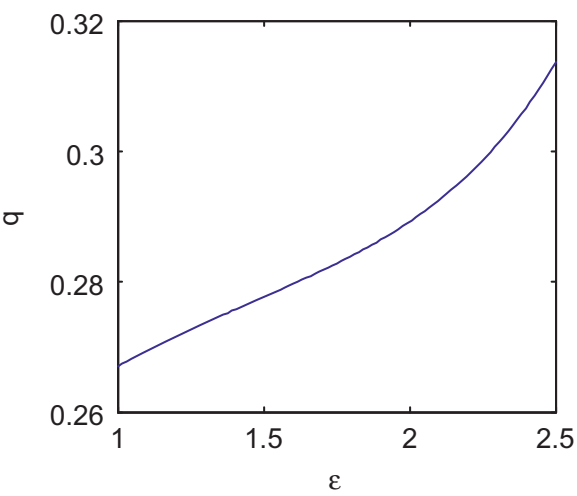

Figure 4: $\alpha=0.6$.

the poor, it strengthens opposition among the rich. At low levels of segregation (up to about 1.7), the effect of stronger opposition of the rich dominates the effect of less interaction with the rich. At higher levels, though, the opposite is true, so the poor opposition starts declining to rich the level of zero in absence of social interaction between the rich and the poor.

Our results also indicate that the level of social spending that maximizes government objective function (as in Figure 3) at benchmark parameter values are robust to introduction of some segregation $(\varepsilon \leq 1.5)$, but then changes discretely to the extreme that pleases the rich. This pattern however varies with the share of the rich in population: for $\gamma \leq 0.3$ optimal $\alpha$ remains at a high level for any value of segregation parameter. 


\section{Concluding Comments}

Political opinion can be expressed in different ways. In some countries, people express their support or opposition mainly on election day. In other societies, government support or resentment may affect daily life. People strike, demonstrate or violate different laws as a way of expressing their political opinion. This paper focuses on tax evasion as a way of expressing opposition to a regime and on the interdependence between political opinion and legal obedience. Tax evasion is a convenient example as it allows us to use income level as a source of heterogeneity among individuals that is not directly related to government support. However, tax evasion is just one example of such interdependence different types of laws and regulations can be affected by political opinion and at the same time shape them. Because political opinion and law obedience are both typically subject to social interaction, their interesting interdependence should be taken into account when searching for optimal government policies.

Our analysis indicates that social interaction may alter the expected effect of government policy on public support as well as civil disobedience. A policy targeting the poor population may have a large resonance among the rich, and the resulting effect on government popularity and tax compliance may be substantially different from what is expected. We show, for example, that a decrease in social redistribution policy that should, in principle, increase government popularity among the rich, may actually decrease it (depending on the level of this redistribution policy). Therefore, it is important to take into account social interaction effects while ex ante evaluating public policy proposals.

Our contribution to the tax compliance literature is twofold. Firstly, we theoretically model the truly dynamic relation between government support and tax compliance using explicit social interaction rules. The literature before has only considered comparative statics of the relation between political support and other economy-wide characteristics, on one hand, and tax compliance, on the other hand. Second, we provide a framework for studying complicated dynamic effects mediated by social interaction on tax compliance and prove the existence of a unique stable steady state for a class of models in this framework.

Our stylized model is just a small step in the direction of tracing implications of explicitly modeled of social interaction on micro (a match) level for macro (population) level outcomes. It opens various avenues for potentially fruitful research. One of them would be to make political economy component of the model more explicit by introducing electoral competition. This would allow for a closer reflection of political process in democracies within our model. To make such extension more interesting, one would enrich the set of types 
of population by introducing political views heterogeneity and/or third (middle) level of income. Another way to go forward would be look at continuous income scale. While obviously technically challenging, this would ultimately open up the opportunity to calibrate the model from observables. Yet another interesting extension would be to look at the speed of convergence and other properties of opposition/disobedience dynamics rather than focussing on the stable steady state.

Acknowledgemets: I would like to thank James Alm, Aloys Prinz and the participants of IIPF Congress in Uppsala, the EEA Congress in Glasgow and SMYE in Luxemburg for helpful comments. I am greatly indebted to Chaim Fershtman for his overwhelming contribution to a previous version of this paper. I am grateful to an anonymous referee and the editor Burkhard Schipper for their insights and help in getting this paper in shape.

\section{References}

Allingham, M., and A. Sandmo. 1972. "Income Tax Evasion: A Theoretical Analysis." Journal of Public Economics 1:323-38.

Alm, J. 2010. "Testing Behavioral Public Economics Theories in the Laboratory." National Tax Journal 63:635-58.

Alm, J., B. Jackson, and M. McKee. 2009. "Getting the Word Out: Enforcement Information Dissemination and Compliance Behavior." Journal of Public Economics 93:392-402.

Alm, J., and B. Torgler. 2011. "Do Ethics Matter? Tax Compliance and Morality." Journal of Business Ethics 101:635-51.

Andreoni, J., J. Erard, and J. Feinstein. 1998. "Tax Compliance.” Journal of Economic Literature 36:818-60.

Besley, T., I. Preston, and M. Ridge. 1997. "Fiscal Anarchy in the UK: Modeling Poll Tax Noncompliance." Journal of Public Economics 64:137-52.

Bloomquist, K. 2006. "A Comparison of Agent-Based Models of Income Tax Evasion.” Social Science Computer Review 24 (4):411-25.

Castellano, C., S. Fortunato, and V. Loreto. 2009. "Statistical Physics of Social Dynamics." arXiv:0710.3256V2, May 2009.

Cowell, F. 1990. The Economics of Tax Evasion. Cambridge, Mass: MIT Press.

Cummings, R., J. Martinez-Vazquez, M. McKee, and B. Torgler. 2009. "Tax Morale Affects Tax Compliance: Evidence from Surveys and an Artefactual Field Experiment." Journal of Economic Behavior and Organization 70:447-57.

Dulleck, U., J. Fooken, C. Newton, A. Ristl, M. Schaffner, and B. Torgler. 2016. "Tax Compliance and Psychic Costs: Behavioral Experimental Evidence Using a Psychological Marker.” Journal of Public Economics 134:9-18. 
Erard, B., and J. Feinstein. 1994. "Honesty and Evasion in the Tax Compliance Game." Rand Journal of Economics 25:1-19.

Feld, L., and B. Frey. 2007. "Tax Compliance as the Result of a Psychological Tax Contract: The Role of Incentives and Responsive Regulation." Law and Policy 29:102-20.

Fortin, B., G. Lacroix, and M. C. Villeval. 2007. "Tax Evasion and Social Interaction." Journal of Public Economics 91:2089-112.

Frey, B., and R. Jegen. 2001. "Motivation Crowding Theory." Journal of Economic Surveys 15:589-611.

Frey, B., and B. Torgler. 2007. "Tax Morale and Conditional Cooperation." Journal of Comparative Economics 35:136-59.

Gangl, K., E. Hofmann, and E. Kirchler. 2015. “Tax Uthorities' Interaction with Taxpayers: A Conception of Compliance in Social Dilemmas by Power and Trust." New Ideas in Psychology 37:13-23.

Glaeser, E. L., B. Sacerdote, and J. A. Scheinkman. 1996. “Crime and Social Interactions.” The Quarterly Journal of Economics 111:507-48.

Gneezy, U., and A. Rustichini. 2000. "Pay Enough or Don't Pay at All.” The Quarterly Journal of Economics 115:791-810.

Gordon, J. P. F. 1989. "Individual Morality and Reputation Costs as Deterrents to Tax Evasion." European Economic Review 33:797-805.

Huckfeldt, R., P. A. Beck, R. J. Dalton, and J. Levine. 1995. "Political Environments, Cohesive Social Groups, and the Communication of Public Opinion." American Journal of Political Science 39:1025-54.

Lipatov, V. 2008. "Social Interaction in Tax Evasion." MPRA Paper 8829.

Listhang, O., and A. Miller. 1985. "Public Support for Tax Evasion: Self-Interest or Symbolic Politics?" European Journal of Political Research 13:265-82.

Myles, G. D., and R. A. Naylor. 1996. "A Model of Tax Evasion with Group Conformity and Social Customs." European Journal of Political Economy 12:49-66.

Slemrod, J. 2007. "Cheating Ourselves: The Economics of Tax Evasion." Journal of Economic Perspectives 21:25-48.

Schneider, F., and D. Enste. 2000. "Shadow Economies: Size, Causes, and Consequences." Journal of Economic Literature 38:77-114. 